\title{
Examining Organizational Culture and Employee Performance: The Case of the Auditor General's Office, Zambia
}

\author{
Dr. Ron M. Mwambwa, FCMA,CGMA \\ Consultant, EUROSUPPORT (EU Project), Monrovia \\ Liberia \\ Dr. Asif Mahbub Karim, FCGIA \\ Associate Professor and Dean \\ Binary Post Graduate School \\ Binary University of Management and Entrepreneurship \\ Malaysia \\ Dr. Oo Yu Hock \\ Professor and Head at Asia e University \\ Malaysia \\ Dr. Nadia Farhana \\ Assistant Professor \\ Department of Business Administration \\ Stamford University, Bangladesh
}

\begin{abstract}
This study investigated the influence of the Annual Performance Appraisal System (APAS) on employee performance in the Office of the Auditor General (OAG) of Zambia. Specifically, the study focuses on whether organizational culture has an effect on employee performance in the OAG despite the implementation of the Annual Performance Appraisal System. The study used a mixed method approach to collect and analyse data. The results of the study showed that organizational culture can influence employee performance despite implementation of an annual performance appraisal system. The implications of the results reiterate the value of re - designing the APAS so that it takes into account factors such as organizational culture that currently affect its influence on enhancing employee performance in the $O A G$.
\end{abstract}

Keywords: Annual Performance Appraisal System (APAS), Performance Management System (PMS), Organizational Culture.

\section{Introduction}

In 1993, the government of the Republic of Zambia started the Public Service Reform Program (PSRP) in order to make the public service more efficient. The PSRP aimed at strengthening the management capabilities of the government functionaries and improving service delivery. Within the framework of the PSRP was the Performance Management System (PMS) that aimed at ensuring that organizational and individual performance was assessed against set targets and objectives. Within the performance management framework, performance appraisal was emphasized through the introduction of the Annual Performance Appraisal System (APAS).It was an open system designed to help employees in the Zambian public service to plan, manage, evaluate and realize performance improvements with the aim of achieving organizational goals.

\section{Definitions}

\subsection{Performance Management System}

Waggoner, Neely, and Kennerly (1999) opined that performance measurement in business serves the purpose of monitoring performance, identifying the areas that need attention, enhancing motivation, improving communication and strengthening accountability. Labas (1995) characterized performance management system as the philosophy supported by performance measurement. It is the organization wide shared vision, teamwork, training, incentives that surround the performance measurement system (Nudurupati. Bititci, Chan, 2011). 
Armstrong and Barron (2002)define performance management as a strategic and integrated approachto delivering sustained success to organizations by improving the performance of the people who work in them and by developing capabilities of teams and individual contributors.PMS is concerned with managing the business in order to gain competitive advantage. When an organization has employees who are performing and meeting targets, the profits are generated and Shareholder Value is increased. In the case of a public sector organization, efficiencies in service delivery are achieved.

According to Torrington, Hall, Taylor and Atkinson (2014), the conceptual foundation of performance management relies on the view that performance is more than ability and motivation. It is argued that clarity of goals is key to enabling the employee to understand what is expected and the order of priorities. In addition, goals themselves are seen to provide motivation.

\subsection{Performance Appraisal}

Torrington, Hall, Taylor and Atkinson (2014) stated that individual objectives derived from team objectives and an agreed job description can be jointly devised by manager and employee. These objectives are outcomes/results oriented rather than task oriented, are tightly defined and include measures to be assessed. The objectives are designed to stretch the individual and offer potential development as well as meeting business needs.

\subsection{Organizational Culture}

According to Lim (1995), Schein (1985) viewed culture as comprising three levels:

(1) Behaviours and artefacts: this is the most manifest level of culture, consisting of the constructed physical and social environment of an organization.

(2) Values: being less visible than are behaviours and artefacts, the constituents of this level of culture provide the underlying meanings and interrelations by which the patterns of behaviors and artefacts maybe deciphered.

(3) Basic assumptions: these represent an unconscious level of culture, at which the underlying values have, over a period of time, been transformed and are taken for granted as an organizationally acceptable way of perceiving the world. By this definition, basic assumptions are also the most difficult to relearn and change.

The researcher discusses organizational culture in the context of underlying values which cannot easily be noticed but affect the behavior of employees in the organization, and are taken as the normal way of doing business. These values are so entrenched in the organization that they are so difficult to change even when the organization is not heading in the right direction. New employees coming into the organization quickly pick up this culture and become assimilated into the organizational value systems, traditions, and beliefs.Muma (2017) stated that according to UNESCO (2001), culture should be regarded as the set of distinctive spiritual, material, intellectual, and emotional features of a society or a social grouping, and encompasses, in addition to art and literature, lifestyles, ways of living together, value systems, traditions and beliefs. He further gave definitions by some scholars. Mondin (2005) defined culture as signifying a great quantity of knowledge either in general or in some particular sector. Secondly, where culture indicates the education, formation and cultivation of man, Gyekye (1997) defined culture and tradition as socially inherited beliefs and practices that profoundly affect the texture of our lives.

\section{Empirical studies on the influence of organizational culture on employee performance}

Going by the definitions of the word "culture", it is clear that it refers to stable set of beliefs, values and behaviours in a society. Gyekye (1997) referred to culture as socially inherited beliefs and practices that profoundly affect the texture of our lives. Culture has been extended to organizations into what is called "organizational culture". The researcher seeks to establish whether there is a link between organizational culture and employee performance. Performance appraisals have always been done in retrospect. In many organizations, this is done once a year while in others, there is a mid - year review. Doing a performance appraisal once a year or indeed every six months means that the organization waits 6 or 12 months before it can know the performance of its employees. In the researcher's view, this is a culture which is developed in the organization and employees grow with the belief that their performance will only be appraised every 6 or 12 months. This means that corrective action cannot be taken until then. These underlying values are so difficult to transform as the employees take them for granted as "the way things are done in the organization". Performance appraisal gives a chance to both the employees and the supervisor to review the goals and the targets to confirm whether the employee are performing to achieve the set targets, how far they are from accomplishing their goals and also to identify any possible challenges that the employee may face and how the challenges can be handled to minimize interruptions in employee performance. The researcher opines that an organization should cultivate a performance culture that will make the employees be continuously accountable for their performance. A culture where employees understand that there is a reward for good performance and that poor performance will have sanctions. 
In the case of the OAG, the APAS looks at past performance of an employee and that explains why it is more focused on measuring past performance against targets. What the APAS has failed to do over the years in the Zambian public sector is to make managers think strategically, in terms of where their organizations want to go and how they can effectively use their employees to achieve the desired results. Again, this is a culture that is so entrenched in the Zambian public service to an extent that during the appraisal process, rarely do managers think of how the APAS links with the objectives of the organization in the strategic plan. Yet, the annual performance appraisal is supposed to be a tool to assess the employee's performance and how the employees contribute to the strategic goals of the organization. Whereas it is good to measure past performance, it should only be important to the extent that it is going to help the organization improve its performance. Therefore, the researcher posits that the annual performance appraisal system should be used to drive organizational performance as past performance may not be an indicator for the future. This is the reason why the researcher opines that the APAS should be closely linked to the organization's strategic plan and organizational culture viewed as a strategic lever that should enhance employee performance.

Most modern organizations rely upon some form of performance appraisal system to provide employees with feedback about their performance and to help the organization make strategic decisions on such matters as achievement of organizational objectives, employee training and engagement and stakeholder management. Increasingly, modern organizations look at organizational culture as one of the key drivers of employee performance and thus, a number of researchers have investigated the effect of culture on organizational performance and how it affects the appraisal systems. Given the definitions of culture, the researcher looks at the value systems of the organization as being critical for its success. The core values of the organization must be understood by all its employees and the employees must undertake to live by those values. It is important for the organization to continuously examine the culture - employee relationship so that the combination leads to enhanced organizational performance. Kim and Yu (2004) concluded that organizational culture impacts a variety of organizational processes and performance. HRM processes that include employee recruitment and promotion processes, retention processes,succession planningand appraisal systems are all affected by organizational culture. If the organization is accustomed to making its recruitments and promotions in a less transparent manner, this is a culture that will be entrenched into the organizational processes and will require the organization to re-examine its processes and change the mindset of its employees to embrace the new processes. Sheridan (1992) concluded that the variation in cultural values had a significant effect on the rates at which the newly hired staff terminated employment. This points to the relationship between organizational culture and organizational processes. Saudi (2014) argued that using the BSC as a strategic performance management system would enable the management's strategy and vision to be translated into realistic and achievable goals. Cooke and Szumal (2000) used the Organizational Culture Inventory to understand the operating cultures of organizations.

They stated that the organizational culture inventory assesses twelve (12) sets of norms that describe the thinking and behavioral styles that might be implicitly or explicitly required for people to "fit in" and "meet expectations" in an organization or organizational sub - unit. The researcher posits that the core values of the organization help shape the organizational direction by defining norms or standards that should guide the employees' behavior and approach to work and how they should relate with one another and the customers. Inculcating organizational culture into employee behavior can be difficult and not every employee will adhere to those values and this is where organizational processes become important. Cooke and Szumal (2000) concluded that culture disconnect, the defensive misattribution of success and the culture by-pass highlight the importance of alignment, systems thinking, and organizational learning to cultural change. Just like many organizations, the OAG needs to bring its mission and goals into alignment with shared values and assumptions and then make appropriate changes or improvements in the systems, structures, technologies, and skills of members of staff. Fletcher (2001) talked about the importance of cultural differences. The applicability of the performance management and performance appraisal systems cannot be the same in the USA as applied in the UK or indeed a developing African country like Zambia. Cultural variables and their influence on appraisals must be considered (Fletcher \& Perry 2001; Milliman et al, 1998). Cox and Blake (1991) carried out a study on managing cultural diversity and implications for organizational competitiveness. With the recent business trends of globalization and increasing ethnic and gender diversity, it is increasingly important for managers to pay attention to cultural differences. Cultural differences often play an important part on how individuals behave in an organization. The organization needs to pay attention and define strategies that will help it harmonize the cultural differences for its benefit. The researcher therefore underscores the importance of organizations to be sensitive about ethnicity and diversity because their employees have different backgrounds. Nazir andZamir (2015) concluded that organizational culture has an influence on the performance and productivity of an organization. It gives guidelines for quality of products, punctuality, safety and other factors affecting the environment. This implores the importance of organizational culture when implementing the organizational strategy. Awadh and Saad (2013) carried out a research on the impact of culture on employee performance. 
They concluded that different values and beliefs based upon employee performance help in organizational association. The organizational culture helps in internalizing joint relationships that lead to the management of effective organizational processes. That the job performance of an organization has strong impact of strong organizational culture as it leads to enhanced productivity and that the values and norms of an organization based upon different cultures has an influence on work force management. These studies also pointed to the fact that there is a link between organizational culture and employee performance. Since employee performance is assessed through the use of performance appraisal systems, employees need to know the benefits and experience the positive results of an appraisal system.

Once this happens, there is a chance that the overall culture of the organization will shift to an achievement culture. Daft (2011) referred to four types of culture; achievement culture, bureaucratic culture, clan culture and adaptability culture. The researcher posits that the different cultures described by Daft are all essential for the organization and should not be mutually exclusive. This is so because the organization needs to focus on its strategic objectives and vision for it to be successful. The organization needs to conduct its business in an orderly manner for it to achieve its objectives and thus leaning to the bureaucratic culture. Further, there is need for employee engagement. The involvement of employees to meet changing expectations is clan culture. The interpretation and translation of signals from the environment is also essential for the organization to survive in the competitive environment and for this reason, the researcher emphasizes the need for organizations to use PMS as a strategic tool that should be used to scan the environment to identify the threats and opportunities for the benefit of the organization. Daft (2011) further stated that of the values that make up an organization's culture, ethical values are considered highly important for leaders and have gained renewed emphasis in the light of today's financial scandals and moral lapses. The researcher argues that bad ethical behavior and moral lapses by top management have the potential to damage the reputation of the organization. In the private sector, if this happens, the share value is likely to go down and therefore has an effect on shareholder value. In the public sector, the public tends to lose confidence in the governance systems.A high performance culture plays an important role in creating an organizational culture that enables learning and innovative response to challenges, competitive threats or new opportunities. A strong culture that encourages adaptation and change enhances organizational performance by motivating employees, unifying people around shared goals and higher mission and shaping and guiding employee behavior so that everyone's actions are aligned with strategic priorities. A number of studies have found a positive relationship between culture and performance. Daft (2011) went on to state that companies that intentionally manage cultural values out - perform similar companies that do not. According to Daft (2011), strong adaptive cultures that facilitate high employee and organizational performance often incorporate the following values. Firstly, the whole is more important than the parts and boundaries between parts are minimized. This is very important because in an organization like the OAG, the employees are aware of the various parts of the organization and in a departmentalized set up, it is very easy for employees to focus only on what concerns their departments forgetting the bigger organizational picture. The researcher posits that the emphasis on the whole reduces the boundaries within the organization. Everyone's primary attitudes and behaviors must reflect the organization's dominant culture. Secondly, equality and trust are primary values. The culture creates a sense of community and caring for one another. The organization is a place for creating a web of relationships that allows people to take risks and develop their full potential. The researcher argues that this is very important because once the employees understand and embrace the organizational culture; the culture will tend to bind them together so that whatever they do, they will have the culture of the organization at the back of their minds. The culture will promote equality in the manner in which employees are treated. Thirdly, the culture that encourages risk taking, change, and improvement. The basic value is to always question the status quo and to take risks that are in the best interest of the organization and the various stakeholders. Constant questioning of assumptions encourages the employees to be creative and thus lead to improved organizational performance. High performance cultures focus both on values and solid business performance as the drivers of organizational performance. Leaders align values with the organization's day- to - day operations hiring practices, budgeting, performance management and appraisal, criteria for promotion and rewards.

The studies reviewed concluded that organizational culture affects employee and organizational performance. A strong organizational culture that is embraced by employees in the organization has a positive effect on the performance of the organization. Lim (1995) concluded that a major obstacle to investigation of the relationship between performance and culture appeared to be related to the application of the term organizational culture. A number of studies appeared to assume that the presence of a strong organizational culture has a positive influence on organizational performance. It is important that the organization ensures that the interpretation of its culture is understood by employees, and employees must live by this culture. Barney (2015) concluded that a firm's culture can be a source of competitive advantage if that culture is valuable, rare, and imperfectly imitable. Firms with valuable, rare, or imperfectly imitable cultures should nurture these cultures. 
Firms without valuable, rare or imperfectly imitable cultures cannot expect their cultures to be a source of sustained competitive advantage. The researcher posits that the phenomenon of competitive advantage for an organization is very important. A number of organizations have not looked at organizational culture as a source of competitive advantage and yet research shows that it is actually a source of competitive advantage. As already discussed by the research, culture impacts the performance of employees and the organization. Building a strong culture that binds the employees together to focus on the organizational goals will enhance productivity. There are not so many organizations that can manage this and therefore this can be a unique undertaking specific to that organization and hence a source of competitive advantage. Harris and Ogbonna (2000) undertook a study on leadership style, organizational culture and performance. The study concluded that some evidence exists of the relationship between leadership style and performance. Based on theories that suggested that leadership style and organizational style were linked, it was proposed that organizational culture mediates the association between leadership style and performance. The leader in the organization sets the "tone at the top". Once the leader's focus is to ensure that organizational culture should be taken as a key imperative in the implementation ofthe organization strategy, the chances are that subordinates will follow. Kahumburu, Maru and Korir (2017) study concluded that employee performance is significantly affected by organizational culture dimensions. Rashid, Sambasivan and Johari (2003) study showed that there is a significant correlation between corporate culture and organizational commitment. Both corporate culture and organizational commitment have an influence in the financial performance of organizations. According to Linnenlueke and Griffiths (2010), many scholars suggest that the pathway for adoption of corporate sustainability principles leads via the adoption of sustainability - oriented organizational culture. The study concluded that employees from different culture types placed emphasis on different aspects in their pursuit of corporate sustainability, ranging from internal staff development, resource efficiency, environmental protection or stakeholder engagement. The researcher argues that corporate sustainability can only be achieved if the firm is competitive. To remain competitive, the firm needs to also focus on its organizational culture. The different sub - cultures that exist throughout the organization and members of each sub - culture should be integrated so as to form the main organizational culture. The organization should not allow the sub - culture to take center stage otherwise that can be detrimental to the success of the organization. Gregory, Harris, Armenakis and Shook (2009) investigated organizational culture and effectiveness: A study of values, attitudes and organizational outcomes. The study stated that many managers and management researchers held a view that organizational culture influenced firm effectiveness although very few studies have provided detailed insight into this relationship.

The facts that have been discussed in the different studies on the effect of culture on employee performance underpin the fact that culture cannot be ignored in an organization. The studies highlighted above have underscored the importance of culture when implementing performance management and appraisal systems. However, it is important for the organization to consider at what point culture should be considered and by whom and how. The studies reviewed did not seem to answer these questions. This study fills the gap through the use of the Balanced Scorecard and emphasizes the need to consider culture right at the time of developing the organizational strategy as part of the learning and growth perspective.

\section{Research design and methodology}

The study used a mixed research method to collect and analyse data. According to Johnson \&Onwuegbuzie (2004), a mixed research is a class of research where the researcher mixes the qualitative and quantitative research techniques, methods, approaches, concepts or language into a single study. Specifically, the researcher used the concurrent embedded strategy approach, also referred to as the concurrent nested mixed method design (Creswell, Plato, Clark, et al., 2003). According to Creswell (2003), the concurrent embedded strategy approach can be identified by its use of one data collection phase, during which both qualitative and quantitative data are collected simultaneously. The concurrent embedded approach has a primary method that guides the project and a secondary database that provides a supporting role in the procedure. In this study, data collection using a questionnaire was the primary method and the semi structured interviews was the secondary method. According to Morse (1991), a primary qualitative design could embed some quantitative data to enrich the description of some sample participants. Prior to the collection of the data, the questionnaire was tested for reliability and validity using Cronbach's Alpha reliability test which gave an Alpha value of $0.98(\alpha=0.98)$.

The study had a sample size of 150 out of a target population of 593 and purposive sampling was used to pick the sample from all levels within the organization. The questionnaire was administered to 120 participants and 67 participantsresponded, representing 55.8\%. Semi - structured interviews were carried out with 8 employees. Although researchers suggest saturation to occur at 12 participants in a homogeneous group, 
Crouch \& McKenzie (2006) stated that for practical reasons, participants of less than twenty (20) in a qualitative research helps the researcher to build and maintain a close relationship. This improves the open and frank exchange of information on the subject matter and helps mitigate some of the biases and validity threats inherent in qualitative research.The data was analyzed using Statistical Package for Social Scientists (SPSS). The SPSS enabled the researcher to come up with frequencies and percentages on the variables that were analyzed. Further, Chi - Square tests and correlation tests wereperformed.

\section{Research Findings and discussion}

Research has shown that if employees are committed and having the same norms and values as those in the organization, employee performance is likely to increase towards achieving organizational goals. In order to determine whether culture had an influence on the implementation of the annual performance appraisal system as a tool that could enhance employee performance in the OAG, the study started by investigating whether employees understood the purpose of the APAS. This was necessary because without this understanding, it could be difficult for the organization to successfully integrate the appraisal system into the culture of the organization for better employee performance. The results of the research showed that a number of staff in the OAG understoodthe purpose of the annual performance appraisal system as can be seen in figure 1 below where a total of $62 \%$ either agreed or strongly that employees in the OAG understood the purpose of the APAS. Although 33\% either disagreed or strongly disagreed, it was clear that the purpose of the APAS was well understood.

However, the organization has not leveraged on this strength to ensure that the benefits of the APAS are explained to the employees so that the organization derives value from the system through improved employee performance. Figure 2 shows that the majority of employees (97\%) either agreed or strongly agreed that despite the implementation of the APAS in the OAG, organizational culture played an important role in influencing the performance of employees in the OAG. The researcher opines that given this result, it is important for the organization to consider organizational culture as a strong driver of employee performance. Therefore, this means that the organization should consider organizational culture at the time of developing the organizational strategy and ensure that appropriate interventions and measures are embedded in the strategy. Organizations can have strong performance evaluation systems but if the organizational culture is not correct, enhancement of employee performance remains a challenge. This assumption is confirmed by the results of the study in that the majority of employees $(66 \%)$ in the OAG either disagreed or strongly disagreed that the implementation of the APAS can improve employee performance while only $30 \%$ either agreed or strongly agreed. The belief in the organization is that the APAS is just another government requirement without significance on employee performance. This is a culture that is entrenched in the organization. This was despite the results of the chi-square test showing significant evidence of a relationship between implementation of the APAS in the OAG and enhancement of employee performance given the chi-square values of ${ }^{2}(4)=41.879$, p-value $<.05$. Figure 3 . The disagreement by the participants that the implementation of the APAS does not lead to enhanced employee performance points to one thing, that enough has not been done to explain the linkage between organizational goals and individuals goals within the organization and how the organization monitors and evaluates employees to ensure achievement of organizational goals. What is also clear is that although organizations talk about organizational culture, this has not been clearly defined. The organization has the majority of employees assuming that organizational culture influences the performance of employees but only referring to organizational culture in abstract without a clear definition of what it is in the context of the OAG and how it can be measured.

When the employees were asked to identify other factors that influenced the implementation of the APAS, poor cultural behavior was identified as one of the factors. Though not categorized as one of the major factors according to the analysis in table 1 below, the findings of the study show that organizational culture is one of the major drivers of employee performance. Organizational culture defines how the organization and the employees behave in the pursuance of meeting the organizational objectives. It gives guidelines for quality of products, employee conduct and how the employees should relate with the various stakeholders. The findings of the survey showed that organizational culture plays an important role in influencing the performance of employees in the OAG. This is very significant and the researcher believes that the OAG should begin to pay more attention to the organizational culture so as to enhance the performance of its employees.

\section{Conclusion and implication}

The researcher is cognizant of the difficulties in making conclusions about the relationship between employee performance and organizational culture. Part of the difficult being that when we are talking about organizational culture, what are we really talking about and can it be clearly defined so that the behavior of employees can be measured against something that is measurable. 
Measuring organizational culture against measures such as the quality of goods and services being produced by the organization does not give the true measurement of organizational culture which is really a manifestation of underlying values which cannot easily be noticed but affect the behavior of employees in the organization. Further, Bernard Lim (1995) submitted that a number of studies appear to assume that the presence of a strong culture has a positive influence on organizational performance without taking into account the influence of sub - cultures. The researcher opines that sub - cultures have an effect on the overall organizational culture of the organization and therefore should not be ignored. Organizational culture should be embedded into the organizational strategy so that even those joining the organization know what the core values of the organization are. Those core values should be entrenched into the organizational culture. The organization should ensure that its culture is effectively communicated across functions and business units by top management through business unit managers. This study also emphasizes the need for an effective leadership that will ensure that the culture of the organization is understood by employees in the organization. The implication is that once the culture of the organization is strong, those intending to manipulate the organization will find it difficult.

\section{Figures and tables}

\section{Figure 1-Distribution of participants with knowledge of the purpose of the APAS}

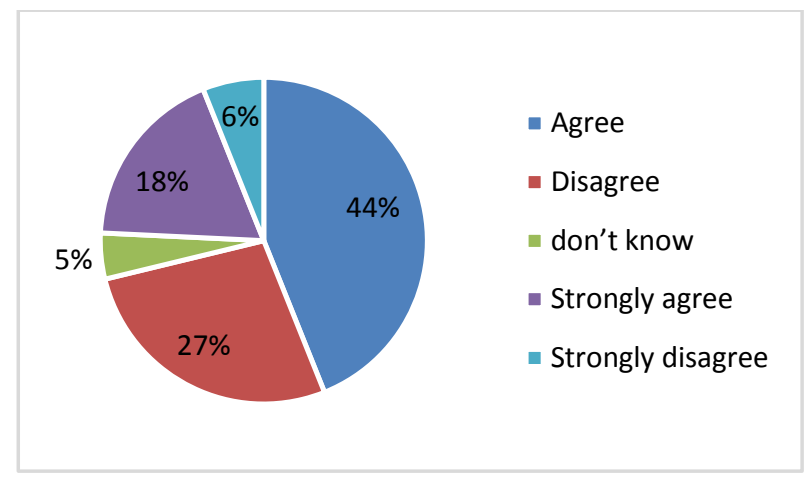

Figure 2- Implementation of the APAS and organizational culture

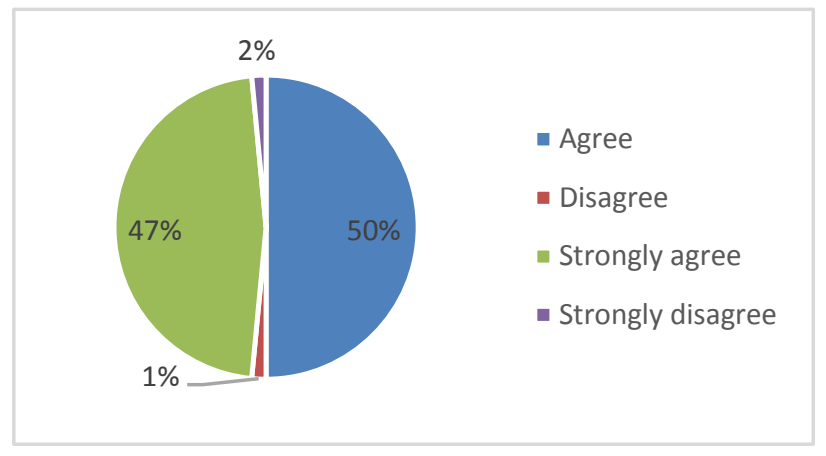

Figure 3 - Implementation of the APAS and improved employee performance

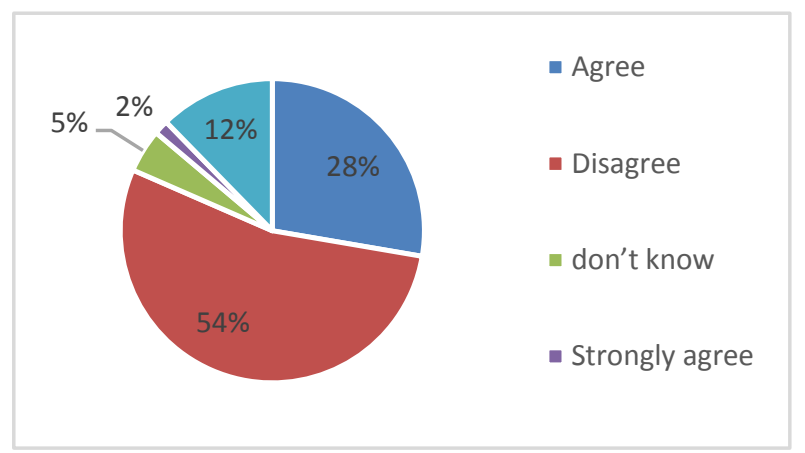




\section{Table 1 - Other factors that influence enhanced employee performance}

\begin{tabular}{|c|c|c|}
\hline Response/Variable & $\begin{array}{l}\text { Frequency/No. } \\
\text { respondents }\end{array}$ & $\begin{array}{l}\text { Percentag } \\
\text { e }\end{array}$ \\
\hline Lack of performance rewards & 16 & 10.26 \\
\hline Lack of training & 16 & 10.26 \\
\hline Low funding & 11 & 7.05 \\
\hline Lack of motivation & 10 & 6.41 \\
\hline Inadequate laptops & 7 & 4.49 \\
\hline non revision of job descriptions & 5 & 3.21 \\
\hline Lack of objectivity by management & 5 & 3.21 \\
\hline Lack of openness and transparency by some supervisors & 5 & 3.21 \\
\hline Lack of staff welfare support & 5 & 3.21 \\
\hline Low Salary & 4 & 2.56 \\
\hline Lack of real time feedback on APAS & 4 & 2.56 \\
\hline Delayed feedback on APAS & 3 & 1.92 \\
\hline Communication gap between top management and general staff & 3 & 1.92 \\
\hline Failure to rotate auditors & 3 & 1.92 \\
\hline Favoritism & 3 & 1.92 \\
\hline Inadequate supervision by responsible officers & 2 & 1.28 \\
\hline Segregation & 2 & 1.28 \\
\hline Nepotism & 2 & 1.28 \\
\hline $\begin{array}{l}\text { Uncertainty and speculation as a result of acting positions in senior } \\
\text { management positions }\end{array}$ & 2 & 1.28 \\
\hline Failure to involve all staff when setting up Targets & 2 & 1.28 \\
\hline Poor decision making by top management & 2 & 1.28 \\
\hline APAS are only done for the purpose of confirmation on first app & 2 & 1.28 \\
\hline Lack of performance monitoring system & 2 & 1.28 \\
\hline Unfairness in recommending staff for promotions & 2 & 1.28 \\
\hline Segregation in terms of promotion and training & 2 & 1.28 \\
\hline wrong interpretation of Cabinet Circulars by management & 2 & 1.28 \\
\hline Poor communication & 2 & 1.28 \\
\hline Failure by management to recognize efforts by supervisors & 2 & 1.28 \\
\hline Poor supervision by supervisors & 2 & 1.28 \\
\hline Lack of modern tools. & 1 & 0.64 \\
\hline Too much idle time & 1 & 0.64 \\
\hline Non completion of the audits & 1 & 0.64 \\
\hline Lack of action by relevant authorities on some queries raised & 1 & 0.64 \\
\hline Unclear legislation & 1 & 0.64 \\
\hline Rewarding non- performers & 1 & 0.64 \\
\hline Poor demographic structure of staff & 1 & 0.64 \\
\hline Allegiance to individual managers & 1 & 0.64 \\
\hline Limited opportunities & 1 & 0.64 \\
\hline Defective constitution & 1 & 0.64 \\
\hline Poor cultural behavior & 1 & 0.64 \\
\hline Ineffective Leave Plan & 1 & 0.64 \\
\hline Poor succession plan & 1 & 0.64 \\
\hline Inadequate fleet of motor vehicles & 1 & 0.64 \\
\hline Lack of pension plans & 1 & 0.64 \\
\hline Lack of social activities like team building & 1 & 0.64 \\
\hline Lack of staff mentors & 1 & 0.64 \\
\hline Lack of clear set goals to be achieved & 1 & 0.64 \\
\hline Failure to link overall organizational goal with individual goal & 1 & 0.64 \\
\hline Poor record management of documents in personal files & 1 & 0.64 \\
\hline
\end{tabular}




\begin{tabular}{|l|l|l|}
\hline Lack of clear policy on APAS & 1 & 0.64 \\
\hline Poor working conditions & 1 & 0.64 \\
\hline Inadequate staff engagement & 1 & 0.64 \\
\hline Retirement age not properly defined & 1 & 0.64 \\
\hline Greediness by management & 1 & 0.64 \\
\hline Poor quality control reviews & 1 & 0.64 \\
\hline Too many meetings involving senior officers during peak periods & 1 & 0.64 \\
\hline Lack of segregation of duties & 1 & 0.64 \\
\hline Total (Valid) & 156 & 100.00 \\
\hline Missing & 0 & 0.00 \\
\hline Total & 156 & 100.00 \\
\hline
\end{tabular}

\section{References}

Armstrong, M. \& Baron., A. (2002). Strategic Human Resource Management, Chartered Institute of Personnel and Development, London,(Part III).

Awadh, A., M. \& Saad, A., M. (2013). Impact of organization culture on employee performance. International review of management business research,2,(1), 168-175.

Barney, B., J. (2015). Organizational culture: Can it be a source of sustained competitiveadvantage? the Academy of Management Review, 11, (3), 656-665.

Cooke, R., A. \& Szumal, J., L. (2000). Using the organization culture inventory to understand the operating cultures of organizations. Handbook of organization culture and synergistics, $147-167$.

Cox, T.,H. \& Blake, S. (1991). Managing cultural diversity: Implications for organizational competitiveness. The Executive, 5, (3), 45-56.

Cresswell, J., W. \& Plano - Clark, V., L. (2007). Designing and constructing mixed research methods. London: Thousand Oaks. In Sing P and Twalo T (2014).

The impact of internal organizational facotrs on the inappropriate job perfprmance and behaviour of employees: A case study. International Business and Economic Research Journal,13,(5), 939 - 954.

Crouch, M. \& McKensie., H. (2006). The logic of small samples in interview - based qualitative research. Social Science Information, 45 (4), $483-499$.

Daft, R.,L. (2011). Leadership( $5^{\text {th }}$ ed). South - Western, Cengage Learning,(Chapter 14).

Fletcher C. (2001). Performance appraisal and management: The Developing Research

Agenda. Journal of Occupational and Organizational Psychological. 473- 487.

Gregory, T., B., Harris, G., S., Armenakis. A., A., \& Shook. L., C. (2009). Organizational culture and effectiveness: A study of values, attitudes, and organizational outcomes. Journal of Business Research, 62, 673-679.

Johnson., B.,R. \& Onwuegbuzie., J., A. (2004). Mixed methods research: A Research Paradigm whose time has come. Educational researcher, 33, (7), $14-26$.

Kahumburu, N., N., Maru, L. \& Korir, M. (2017) Organizational culture and employee performance in Scripture Union of Kenya. Stratford Peer Reviewed Journal and Book Publishing Journal of Human Resource \& Leadership, 1, (2), 58-81.

Kim Jean Lee,S. \& Yu, K. (2004). Corporate culture and organizational performance. Journal of management phychology, 19, (4), $340-349$.

Linnenluecke.K., M., \& Griffiths. A. (2010). Corporate sustainability and organizational culture. Journal of World Business, 45, 357-366.

Lim, B. (1995). Examining the organizational culture and organizational perfomance link. Leadership and Organizational Development Journal,16, (5), 16-21.

Muma, C.,P. (2017). Tradition and Edcucation for All (EFA) among the Baila people of Namwala, Southern Province, Zambia. A thesis for the award of the Degree of Doctor of Philosophy in Exducation and Development.

Nazir, N., Zamir, S. (2015), Impact of Organizational culture on employee's performance. Industiral Engineering letters, ISSN $2224-6096$ Vol. 5, No.9.

Nudurupati,S.,S., Bititci, U.,S, Kurma,V. \& Chan, F.,T.,S. (2011).State of the art review on performance measurement, computers and industrial engineering, 60 (2),279-290.

Ogbonna, E. \& Harris.,C.,L. (2000). Leadership style, organizational culture and performance: Empirical evidence from UK Companies. International Journal of human resource Management, 11, 766 - 788. 
Rashid, A.,Z.,Sambasivan, M.,\& Johari,J. (2003). The influence of corporate culture and organizational commitment on performance. Journal of Management Development, 22, (8), 708-728

Saudi, M., H., M. (2014). The effects of the performance management system and organization culture on the employees attitude in the Malaysian governmentstatutory bodies: A case study of Majlis Amanah Rakyat (MARA): A thesis for the DBA degree, Southern Cross University.

Sheridan, J.E. (1992). Organization culture and employee retention. The Academy of Management Journal, (5), 10361056.

Torrington, D., Hall. L., aylor, S., Atkinson, C. (2014). Human Resource Management, (9 ${ }^{\text {th }}$ ed.), Pearson, (Chapter 10). Waggoner, D.,B., Neely,A. \& Kinnerley, M. (1999). The forces that shape organizational performance measurement system: An interdisplinary review. International Journal of production economics, 60-61, 53-60. 